\title{
UM ESTUDO SOBRE AÇÕES SOCIAIS DO ESTADO BRASILEIRO DIRECIONADAS AO IDOSO E A CONTRIBUIÇÃO DO IFRN ALUSIVA A ESSA TEMÁTICA
}

\author{
B. F. XAVIER
}

Instituto Federal do Rio Grande do Norte

betania.franca@ifrn.edu.br

\section{RESUMO}

O presente artigo tem por objetivo evidenciar o desempenho do Estado no que diz respeito a ações sociais de atendimento ao idoso. O texto destaca os "Marcos Sociais" brasileiros em prol do idoso, bem como as primeiras medidas políticas do Estado direcionadas a este grupo etário. Discorre acerca da Constituição de 1988 e a contemplação, em seus artigos, no que tange a atenções e cuidados quanto a um tratamento adequado ao idoso como pessoa cidadã possuidora de direitos. Á seguir, são abordadas a Política Nacional do Idoso e o
Estatuto do Idoso, como importantes ações sociais realizadas pelo Estado. E por fim, o trabalho enfatiza as iniciativas e propostas de diversos Ministérios do governo relacionadas ao atendimento das demandas presentes no contexto do idoso, bem como a ocorrência de acontecimentos significativos alusivos a essa temática. Ressaltando a possível contribuição do IFRN para o Estado do RN, quanto a uma política de promoção de ações sociais direcionadas ao idoso.

PALAVRAS-CHAVE: Idoso. Ações Sociais. Estado.

\section{A STUDY ON SOCIAL ACTIONS DIRECTED TO THE BRAZILIAN STATE OF THE OLD AND THE CONTRIBUTION TO THIS SUBJECT IFRN ALLUSIVE}

\begin{abstract}
This article aims to highlight the performance of the Govern mentregarding the actions of social assistance to the elderly. The report highlights "Social Marcos" Brazilians in favor of the elderly, as well as the first steps of the state policy directed to this age group. Talks about the 1988 Constitution and contemplation in their articles, when it comes to attention and care as the appropriate treatment to the elderly citizen as a person possessing rights. The following are addressed to the
\end{abstract}

National Policy for the Elderly and the Elderly, as important social actions taken by the State. Finally, the paper emphasizes the initiatives and proposals from various related government ministries to meet the present demands in the context of the elderly, as well as the occurrence of significant events that allude to this theme. Underscoring the potential contribution of IFRN for the state of the RN, as a policy of promoting social activities targeted to the elderly.

KEY-WORDS: Elderly. Social Actions. Government. 


\section{UM ESTUDO SOBRE AÇÕES SOCIAIS DO ESTADO BRASILEIRO DIRECIONADAS AO IDOSO E A CONTRIBUIÇÃO DO IFRN ALUSIVA A ESSA TEMÁTICA}

\section{INTRODUÇÃO}

Observa-se que a política desenvolvimentista que contextualiza as sociedades capitalistas prioriza seus interesses na assistência materno-infantil e no jovem, devido ao retorno potencial de vida útil e produtiva que estes podem possibilitar. Este fato não significa, no contexto histórico brasileiro, a ausência de ações e medidas sociais por parte do governo, que busquem possibilitar um tratamento ao idoso. Porém, estas ações apresentavam-se de forma fragmentada e assistematizada, na dependência da iniciativa e sensibilização de setores e órgãos públicos.

Todavia, há pouco mais de vinte anos no Brasil, tal circunstância encontra-se em estado de mutação e evolução, devido à tomada de consciência social da existência de uma população cujo número vem crescendo acentuadamente; e devido à promulgação, em cinco de outubro de 1988, da Constituição da República Federativa do Brasil, na qual um novo conceito de política social foi materializado em termos da Seguridade Social, compreendendo a Saúde e a Previdência Social. O espírito da Nova Carta foi o de assegurar os direitos sociais a todos os cidadãos brasileiros, com objetivos direcionados a uma nova organização das políticas de previdência, de saúde e de assistência social. Vale ressaltar que a Carta Magna inclui no bojo das citações de seus textos, diversas referências aos direitos dos idosos, sendo, neste sentido, um tanto quanto pródiga no que tange a normas de atenções ao mesmo.

Verifica-se que o segmento que mais cresce na sociedade atual é a população de idosos, e a quantidade de políticas públicas voltadas para eles não atende a demanda, nem tampouco os programas voltados especificamente às necessidades de sociabilidade e cidadania suprem essa carência. No Brasil, acompanhando a tendência mundial, a população de idosos cresce a cada dia, e em 2002 esta população que totalizava 10,6 milhões de habitantes deverá chegar a 32 milhões em 2025 (IBGE, 1991 apud PASCHOAL, 2002). Ressalta-se que o aumento da expectativa de vida do idoso decorre do sucesso de conquistas sociais em diversas áreas, tendo como exemplo o campo da saúde, no qual a Gerontologia, ciência de caráter multidisciplinar que estuda o processo de envelhecimento (NÉRI, 1995), consegue em muitos casos contribuir para uma maior longevidade.

Neste sentido, na atual sociedade globalizada, as ações sociais em prol do atendimento das demandas e necessidades do homem moderno se constituem em uma questão que suscita estudos e desafios, tanto por parte do governo como da iniciativa privada, e vem apresentando, no decorrer dos anos, um maior desenvolvimento quanto à construção de ações que buscam propiciar melhores condições de vida ao ser humano.

Com relação ao idoso, tal questão está sendo elucidada e trabalhada pelo governo brasileiro através de medidas como a "Política Nacional do Idoso", sancionada em 04 de janeiro de 1994 pela Lei no 8.842, que dispõe por meio do Decreto no 1.948 sobre a Política Nacional do Idoso e cria o Conselho Nacional do Idoso, a qual busca beneficiar o cotidiano do idoso no exercício pleno dos direitos e deveres de sua cidadania; e o "Estatuto do Idoso", documento sancionado no dia 10 de outubro de 2003 (Dia Internacional do Idoso) pela Lei no 10.741, que estabelece ao longo de seus 117 artigos um novo marco de vida para homens e mulheres com mais de 60 anos. 
Sob esta ótica, convém destacar, além das medidas acima referendadas, a atuação de diversos Ministérios do governo no que tange a formulação de propostas direcionadas ao atendimento ao idoso, bem como a iniciativa de instituições públicas educacionais, quanto a criação, planejamento e execução, em suas atividades de extensão, de programas e projetos sociais, que visam a saúde, o bem-estar, a cidadania e a melhoria da qualidade de vida a este grupo etário.

\section{UM ESTUDO SOBRE AÇÕES SOCIAIS DO ESTADO BRASILEIRO DIRECIONADAS AO IDOSO E A CONTRIBUIÇÃO DO IFRN ALUSIVA A ESSA TEMÁTICA}

Ao realizar um breve resgate histórico sobre as iniciativas públicas na área de Gerontologia no Brasil, ressalta-se, segundo Barroso (1999), a existência de três marcos históricos de significativa importância na realidade atual, pois explicam certas atitudes e posturas sociais advindas desta herança cultural. Em 1794, o Conde Resende criou a Casa dos Inválidos; o segundo marco deu-se com a instituição do Direito dos Velhos; entretanto, o terceiro marco foi representado pela decisão do Conde de Portugal de não gastar dinheiro com os velhos já que as decisões da iniciativa pública não eram favoráveis à velhice.

Com estas considerações, Barros (1999, p.29-30) enfatiza "[...] uma identificação comum ontem e hoje; não existem dotações orçamentárias para esta classe social [...] depende do nível de sensibilidade pessoal das autoridades." Neste cenário, "A iniciativa pública se manifesta não pelo cumprimento das Leis, pela intencionalidade do interesse coletivo e do bem comum, mas pela visão pessoal dos gestores." (BARROSO, 1999, p.30).

Tal conjuntura não significou a inexistência de ações sociais direcionadas a um tratamento à pessoa madura neste período da história brasileira, porém essas ações apresentavam-se fragmentada e assistematizada. Peixoto (2003), ao abordar historicamente a questão das políticas públicas, destaca que a primeira concessão ao direito à aposentadoria no Brasil foi concedida no de 1890, e que os primeiros direitos trabalhistas foram concedidos após a abolição da escravidão (1888). Entretanto, somente a partir dos anos 20 do século passado, com a Lei Elói Chaves, que cria as Caixas de Aposentadoria e Pensão (CAPs), é que se desenvolveu um sistema de proteção social no interior das empresas.

Nos anos 30 do século passado, segundo Peixoto (2003), o sistema de aposentadorias estendeu-se à maior parte das categorias profissionais, e, em 1933, foi criado o Instituto de Aposentadoria e Pensões dos Marítimos (IAPMs). O que estimulou a fundação, por outras categorias, de seus próprios sistemas de assistência social como o Instituto de Aposentadoria e Pensão (IAPs). Contudo, em 1960, com a criação da Lei Orgânica da Previdência Social, abriu-se caminho para a criação, em 1966, de uma nova lei reunindo as CAPs, IAPMs e IAPs num só instituto, o Instituto de Previdência Social (INPS).

No que diz respeito às políticas públicas sociais voltadas para a velhice, Peixoto (2003) ressalta a criação, em 1973, pelo Ministério do Trabalho e pelo INPS, da aposentadoria-velhice, concedida aos homens de mais de 65 anos e às mulheres de mais de 60 anos; e do decreto-lei de 1974 que estabeleceu uma renda mensal vitalícia (60\% do salário mínimo) para as pessoas de mais de setenta anos. 
Mas, sob a ótica de Peixoto (2003, p.80),

[...] foi somente em 1988, com a nova Constituição brasileira, que se reconheceu, pela primeira vez, a importância da questão da velhice e se estabeleceu que o valor da aposentadoria deveria basear-se no salário mínimo.

Barroso (1999) destaca que a Constituição da República de 1988 explicitou a proteção social aos idosos como dever do Estado e direito do cidadão, colocando de forma hierárquica a família, a sociedade e, em última instância, o Estado, com a obrigação de atendimento a este grupo social. A Constituição da República de 1988, como afirma Faria (2002), foi promulgada em 5 de outubro de 1988 e define, em seu Artigo 6 ${ }^{\circ}$, direitos sociais como sendo: "São direitos sociais a educação, a saúde, o trabalho, o lazer, a segurança, a previdência social, a proteção à maternidade e à infância, a assistência aos desamparados, na forma desta Constituição."

No que tange ao idoso, Faria (2002) destaca que, enquanto os serviços de saúde são universais e a previdência estendida a todos mediante pagamento mensal, a assistência social é destinada a quem dela necessitar. Sendo assim, "A Assistência Social prevista pelo Art. 203 da C.F. inciso $\mathrm{V}$, trata da garantia de um salário mínimo de benefício mensal à pessoa portadora de deficiência e ao idoso que comprove não possuir meios de subsistência ou de tê-la provida por sua família, conforme dispuser a lei". Para dar maior ressalva a esta condição, foi editada a Lei $n^{\circ}$ 8.742 de 7 de dezembro de 1993, "Lei Orgânica da Assistência Social", que explicitou como dever do Estado e Direito do Cidadão a Política de Seguridade Social. Vale ressaltar que na Constituição, conforme destaca Faria (2002), encontram-se ainda no Art. 14, várias referências no que tange aos direitos dos idosos.

Com relação à proteção social como dever do Estado, ocorre a formatação de Leis especiais como a LOAS - Lei Orgânica da Assistência Social, no 7882/93, acima referendada; e a Política Nacional do Idoso, no 8842/94, que contêm uma série de projetos, programas, serviços e benefícios em prol do idoso.

Direcionada ao idoso, Barroso (1999) destaca a existência da Política Nacional do Idoso. Esta política, segundo Barroso (1999, p.34), “[...] fundamentada em subsídios da sociedade civil, foi o momento áureo de esperança cidadã." Sendo assim, surgiu, em 4 de janeiro de 1994, a Lei no 8.842, por meio do Decreto no 1948, que dispõe sobre a Política Nacional do Idoso, cria o Conselho Nacional do Idoso e dá outras providências. Sobre esta Lei, o estudo evidencia o Capítulo IV - Das Ações Governamentais, o qual destaca em seu Art. 10. que, na implementação da Política Nacional do Idoso, são competências dos órgãos e entidades públicos, ações nas área de: promoção e assistência social, saúde, educação, justiça, cultura, esporte e lazer.

Sobre o lazer, a Política Nacional do Idoso em seu Capítulo IV, Art. 10, Inciso VII, enfatiza a ação de incentivar e criar programas de lazer, esporte e atividades físicas que proporcionem a melhoria da qualidade de vida do idoso e estimulem sua participação na comunidade.

Ao abordar o Decreto no 1.948, de 3 de julho de 1996, vale salientar que este regulamenta a Lei no 8.842, de 4 de janeiro de 1994, que dispõe sobre a PNI e dá outras providências. Este decreto determina que na implementação da Política nacional do Idoso, estabelecem-se, aos órgãos e entidades públicas, competências quanto ao atendimento das disposições postas nesta política, enfatizando em seus artigos, que cabem aos Ministérios da Previdência e Assistência 
Social, do Planejamento e Orçamento, da Saúde, da Educação e do Desporto, do Trabalho, da Cultura e da Justiça, competências no que diz respeito ao atendimento e proteção ao idoso.

Nesta conjuntura, convém destacar o Estatuto do Idoso, documento sancionado no dia 1 ㅇ de outubro de 2003 (Dia Internacional do Idoso) pela Lei no 10.741, que estabelece ao longo de seus 117 artigos um novo marco de vida para homens e mulheres com mais de 60 anos, oferecendo proteção aos 20 milhões de brasileiros que já atingiram essa faixa etária, pois fixa direitos que reforçam a precedência da vida sobre todas as coisas e a supremacia do bem comum sobre qualquer privilégio.

Abordando o referido documento o senador Paim declara: "[...] o país terá agora um instrumento tão contundente como o Estatuto da Criança e do Adolescente para garantir a cidadania plena dos idosos." (PAIM, 2004, p.10); e a declaração do senador Demóstenes Torres "O Estatuto do Idoso é uma lei completa e inovadora." (PAIM, 2004, p.10).

Bredemeier e Ruscheinsky (1999) evidenciam a realização de alguns acontecimentos significativos no que diz respeito à construção dos direitos do Idoso na trajetória do tempo, dentre eles destacam-se: a realização, em 1982, do I Encontro Nacional de Idosos; o I Fórum Nacional de Gerontologia, em 1986; o reconhecimento, em 1988, por parte da Constituição da República federativa do Brasil, da "necessidade de atenção à velhice"; o Seminário Nacional "O Idoso na Sociedade Atual", em Brasília (1989); a elaboração, em 1990, do documento "Políticas para a Terceira Idade para os anos 1990", e no corrente ano, a designação de uma Comissão Interministerial para redigir o texto sobre uma política nacional para os idosos brasileiros, o qual se constituiu como "Documento Preliminar da Política Nacional do Idoso".

Sob essa ótica, Bredemeier e Ruscheinsky (1999, p. 103), enfatizam que "A criação e o crescimento do número de grupos de idosos tendem a ser uma resposta às mudanças de sociedade em curso, [...], uma busca de reconhecimento de direitos e de aprimoramento para compreender as mudanças tecnológicas e culturais de sua época."

No que diz respeito à atuação de alguns Ministérios em Prol do Atendimento às Necessidades do Idoso, Figueiredo (1999, p.41) enfatiza que "[...] o objetivo do Ministério da Saúde é instrumentalizar e operacionalizar as questões que dizem respeito à assistência médica e assistência médica sanitária." Por conseguinte, "O propósito da Política Nacional de Saúde do Idoso é promover a saúde do idoso, possibilitando, ao máximo, sua expectativa de vida ativa na comunidade, junto à família e com altos níveis de função e autonomia." (FIGUEIREDO, 1999, p.41). Ressalta-se que tal política, tida como um detalhamento da Política Nacional do Idoso, procura instrumentalizar os artigos já especificados na Lei maior, trabalhando com o conceito de autonomia e altos níveis de função, e com a qualidade de vida. Todavia, é importante ressaltar a necessidade de integração entre o Ministério da Saúde e os demais, para que as ações em prol do idoso possam ser manifestadas de forma completa e abrangente.

Em relação às Políticas do Ministério da Justiça, Barros (1999) afirma que a Secretaria Nacional de Direitos Humanos, criada em 1997, é dividida em quatro departamentos. Dentro desta estrutura, o Departamento dos Direitos humanos é o responsável pelas atividades na área da Terceira Idade.

Segundo Barros (1999), no campo das leis, a legislação pertinente à população idosa tem se difundido por todo o país tanto em nível federal, estadual como municipal. Entretanto, verifica-se que "[...] a população idosa enfrenta o desconhecimento dos seus direitos e deveres 
segundo a lei." (BARROS, 1999, p.50). Barros (1999) ressalta as tentativas de articulação do Ministério da Justiça com o Ministério Público, com a intenção de atingir os Órgãos que fiscalizam as leis.

Quanto às Políticas do Ministério do Trabalho, de acordo com Peppe (1999), este órgão possui três instrumentos relacionados à população idosa: o PROGER (Programa de Geração de Emprego e Renda), o PLANFOR (Programa Nacional de Qualificação do Trabalhador), e o Seguro Desemprego. Nestes três setores, existe uma razoável participação dos idosos com relação aos recursos do FAT (Fundo de Amparo ao Trabalhador), o qual é recolhido nas empresas pelo PIS/Pasep. Peppe (1999) evidencia que o ponto de referência tido como guia deste trabalho é a Política Nacional do Idoso.

Em relação às Políticas do Ministério da Previdência e Assistência Social, ao apresentar as políticas governamentais de atenção à velhice no âmbito da Assistência Social, Mendonça (1999), alude que a prevenção ou o retardamento das condições crônicas e incapacitantes que acompanham o processo de envelhecimento pode ser realizada através de intervenções não só da área médica, como também da social, econômica e ambiental.

No âmbito das Políticas Públicas, para Mendonça $(1999$, p.57)

[...] duas perspectivas devem estar presentes na implementação da Política Nacional do Idoso. [...] a segunda da participação e da inclusão do idoso no processo de formulação, realização e efetivação dessas políticas.

Este contexto em prol do idoso, segundo Mendonça (1999), decorre da existência, no Brasil, de uma política destinada a esta faixa etária (Lei 8.842), a Política Nacional do Idoso.

Quanto à Assistência Social no Brasil, prevista na Constituição Federal de 1988 e regulamentada pela Lei no 8.742, de 07 de dezembro de 1993 - Lei Orgânica da Assistência Social (LOAS) -, esta, para o autor, é considerada uma política pública, sendo uma responsabilidade social tanto da sociedade quanto do Estado.

Entretanto, para uma real implantação da PNI ocorrem dificuldades:

[...] a ausência de divulgação da Política Nacional do Idoso nos meios de comunicação de massa, o descumprimento da legislação, a falta de financiamento adequado, a escassez de dados estatísticos para o desenvolvimento das ações de governo e a inexistência de banco de dados [...]. (MENDONÇA, 1999, p.62),

Para Berquó (1999, p.38)

A questão do idoso no país deve merecer cada vez mais o interesse dos órgãos públicos, dos formuladores de políticas sociais e da sociedade em geral, dado o volume crescente desse segmento populacional, seu ritmo de crescimento e de suas características demográficas, econômicas e sociais. [...] o envelhecimento, como um processo, representa novas demandas por serviços, benefícios e atenções que se constituem em desafios para governantes e sociedades do presente e do futuro. 
Evidencia-se, desta forma, a importância social que o idoso vem adquirindo com a evolução dos direitos e normas por ele conquistados.

Por conseguinte, segundo Faria (2002, p. 80)

[...] uma longa trajetória resta ainda a ser percorrida para que haja um conhecimento da legislação existente e das formas de fazermos valer esses direitos. Há necessidades de maior socialização dessas informações junto aos idosos, bem como de maior conhecimento dos legisladores em Gerontologia Social, para que os dispositivos legais venham ao encontro das necessidades dessa categoria [...]. (FARIA, 2002, p. 80).

Convém salientar a relevância da atuação do Estado, através de leis, estatutos e medidas, como as já citadas "Política Nacional do Idoso" e "Estatuto do Idoso", no que tange ao estímulo e subsídios legais sob o ponto de vista constitucional, de forma que apoiem e permitam a instituições públicas, como também a entidades e órgãos da iniciativa privada, executar ações que promovam a qualidade de vida e um tratamento adequado ao idoso.

Nesta perspectiva, visando o atendimento ao idoso, indivíduo que, a cada dia, segundo dados estatísticos do IBGE (PASCHOAL, 2002) aumenta o seu índice populacional, o que por sua vez conduz à necessidade do aumento de políticas sociais que o auxiliem na busca de uma melhor qualidade de vida e do exercício pleno de sua cidadania, o presente estudo coloca em evidência o "Projeto Saúde e Cidadania na Melhor Idade", programa que faz parte das atividades de extensão do Instituto Federal de Educação, Ciências e Tecnologia do Rio Grande do Norte (IFRN) Natal Campus Central.

Esta proposta social, implantada em 22 abril de 2000, tem como objetivo construir, junto ao idoso, um novo conhecimento sobre a terceira idade, estimulando-o e conscientizando-o de suas potencialidades físicas e psicológicas, tornando assim a sua participação social mais efetiva em prol da melhoria da qualidade de vida e do resgate da cidadania. Vale salientar que o referido Projeto teve como estímulo e base para sua fundamentação e consolidação, o respaldo legal e constitucional encontrado no Estatuto do Idoso (PAIM, 2004), que, em seu capítulo V, artigo 20, refere-se ao direito do idoso à educação, diversão, cultura, esporte e lazer e nos artigos 21 e 25 diz que o Poder Público criará oportunidades de acesso à educação e apoiará a criação de universidade aberta para pessoas idosas bem como a publicação de livros e periódicos adequados ao idoso, respectivamente.

O Projeto funciona nas instalações do IFRN Natal Campus Central e oferece atividades tais como; ginástica; hidroginástica; karatê; dança; natação; oficinas de arte; cursos de línguas e de informática; além de palestras, passeios, excursões e festas.

Observa-se que a ampla infraestrutura do Instituto contribui para viabilizar, com responsabilidade e qualidade, a realização de vivências de lazer que estimulam o convívio e a socialização entre os idosos participantes.

Neste contexto vale ressaltar, em processo de andamento, a Proposta, de difusão e interiorização de "Programas de Atendimento ao Idoso" nos Campi do IFRN. Que tem como intuito oportunizar, a essa classe etária, a vivência de atividades em prol do atendimento das demandas oriundas do processo de envelhecimento, e que se fazem presentes no seu cotidiano. 
A mesma propõe, como objetivo de seus referidos programas de atendimentos, a participação em vivências de lazer que estimulem uma educação conscientizadora com vistas a um envelhecimento saudável com cidadania e qualidade de vida. Vale ressaltar que os referidos programas terão como base de fundamentação teórico-prática, a proposta de trabalho do "Projeto Saúde e Cidadania na Melhor Idade" do IFRN Natal Campus Central.

Para melhor viabilizar a interiorização da Proposta, foi sugerido um Protocolo de Implantação nos Campi que aderirem ao "Programa de Atendimento ao Idoso" (PAI), contendo os passos a seguir elencados: adesão do Campus à Proposta do PAl; visita ao Campus para apresentação da Proposta aos membros das equipes executantes; oficinas sobre as atividades desenvolvidas no Projeto Saúde e Cidadania na Melhor idade; e debates para troca de experiências e para sistematização e operacionalização do processo de implantação da Proposta.

\section{CONCLUSÃO}

Denota-se, no estudo proposto, a importância da atuação do Estado no que diz respeito a iniciativas e medidas em prol de um atendimento ao idoso que o auxiliem em seu processo de envelhecimento, com vistas à cidadania e a aquisição de uma melhor qualidade de vida. Neste sentido, vale ressaltar relevantes ações sociais por parte do governo como a promulgação da Constituição da República Federativa do Brasil que inclui no bojo de suas citações diversas referências aos direitos dos idosos, a Política Nacional do Idoso, o Estatuto do Idoso, e as propostas destacadas por alguns Ministérios relacionadas a esta questão, as quais oportunizam ao idoso, a possibilidade de viver a vida de forma mais digna e salutar, em direção a uma longevidade com qualidade.

Entretanto, observa-se que a quantidade de políticas públicas voltadas ao idoso não atendem a crescente demanda desta população. Fato decorrente do aumento da expectativa de vida do idoso que lhe possibilita uma maior longevidade no contexto social brasileiro.

Convém destacar que em uma sociedade capitalista globalizada, onde imperam a lógica do mercado e a produtividade, a sobrevivência se faz tarefa dificultosa aos adultos considerados produtivos, quiçá às pessoas pertencentes à idade madura. Por conseguinte, observa-se na sociedade brasileira, um desconhecimento por parte do idoso das políticas existentes, que visam favorecer a sua longevidade e proporcionar, por meio de medidas que evidenciam cuidados e atenção, um tratamento adequado a este grupo etário. Sob esta ótica, cabe ao Estado e a sociedade a tomada de providências no sentido de informações que propiciem ao idoso uma maior conscientização quanto ao conhecimento dos direitos que possui rumo ao exercício de uma cidadania plena e com qualidade.

Nesta perspectiva, vale ressaltar o importante papel que o IFRN, enquanto instituição pública de ensino, pode vir a desempenhar no Estado do Rio Grande do Norte, no que diz respeito a políticas que visem ações sociais de cunho educativo direcionadas ao idoso, em prol de sua cidadania e da melhoria de sua qualidade de vida no processo de envelhecimento.

Igualmente, evidencia-se a existência, em processo de andamento, da Proposta de Difusão e Interiorização do "Programa de Atendimento ao Idoso" nos Campi do IFRN, que possui como objetivo em seu referido Programa, possibilitar a participação do idoso em vivências de lazer que estimulem uma educação conscientizadora e emancipadora em prol de um 
envelhecimento saudável face aos desafios presentes no seu cotidiano. Vale ressaltar que os referidos programas de atendimento ao idoso terão como base de fundamentação teóricaprática, a proposta de trabalho do "Projeto Saúde e Cidadania na Melhor Idade" realizado no IFRN Natal Campus Central.

\section{REFERÊNCIAS}

1. BARROS, Herbert Borges. Políticas do Ministério da Justiça. A terceira idade, Assembléia nacional de idosos, São Paulo, 1999, no 17, p. 49-56, agosto.

2. BARROSO, Maria José de Rocha. A iniciativa pública e privada nos serviços de saúde, educação, cultura e lazer. A terceira idade, Assembléia nacional de idosos, São Paulo, 1999, № 17, p. 28-38, agosto.

3. BERQUÓ, Elza. Considerações sobre o envelhecimento da população no Brasil. In: NERI, Anita Liberalesso; DEBERT, Guita Grin (Org). Velhice e sociedade. Campinas: Papirus, 1999. (Coleção Vivaidade).

4. BRASIL. Política nacional do idoso. Declaração universal dos direitos humanos. Programa nacional de direitos humanos. Brasília: Ministério da Justiça, Secretaria Nacional dos Direitos Humanos, 1998.

5. BREDEMEIER, Sônia M. L.; RUSCHEINSKY, Aloísio. Revendo uma trajetória e procurando caminhos na busca da garantia dos direitos dos idosos. In: WOLFF, Suzana Hübner (org). Vivendo e envelhecendo: recortes de práticas sociais nos núcleos de vida saudável. São Leopoldo: Ed. UNISINOS, 2009.

6. PAIM, Paulo senador. Estatuto do Idoso. Brasília: Senado Federal, 2004.

7. FARIA, Mara de Mello. O idoso na legislação brasileira. In: NETTO, Matheus Papaléo (org). Gerontologia: a velhice e o envelhecimento em visão globalizada. São Paulo: Editora Atheneu, 2002.

8. FIGUeIREDO, Ana Maria. Políticas do Ministério da Saúde. A terceira idade, Assembléia nacional de idosos, São Paulo, 1999, no 17, p. 41-46, agosto.

9. MENDONÇA, Políticas do Ministério da Previdência e Assistência Social. A terceira idade, Assembléia nacional de idosos, São Paulo, 1999, no 17, p. 57-62, agosto.

10. MORAGAS, Moragas Ricardo. Gerontologia Social: envelhecimento e qualidade de vida. São Paulo: Paulinas, 1997.

11. NERI, Anita Liberalesco. Psicologia do envelhecimento: uma área abrangente. In: NERI, Anita Liberalesco (Org). Psicologia do envelhecimento: temas selecionados na perspectiva de curso de vida. Campinas: Papirus, 1995. (Coleção Viva Idade).

12. PASCHOAL, Sérgio Márcio Pacheco. Epidemiologia do envelhecimento. In: NETTO, Matheus Papaléo (Org). Gerontologia: a velhice e o envelhecimento em visão globalizada. São Paulo: Atheneu, 2002.

13. PEIXOTO, Clarice. Entre o estigma e a compaixão e os termos classificatórios: velho, velhote, idoso, terceira idade... In: BARROS, Myriam Moraes Lins de. Velhice ou Terceira Idade? Estudos antropológicos sobre identidade, memória e política. 3. ed. Rio de Janeiro: Editora FGV, 2003.

14. PEPPE, Atílio Machado. Políticas do Ministério do Trabalho e Emprego. A terceira idade, Assembléia nacional de idosos, São Paulo, 1999, no 17, p. 54-56, agosto. 